\title{
ГЕНЕТИЧЕСКИЕ ИССЛЕДОВАНИЯ ПЕРИОДИЧЕСКОЙ БОЛЕЗНИ У НАСЕЛЕНИЯ АЗЕРБАЙДЖАНА
}

\section{GENETIC RESEARCH OF FAMILIAL MEDITERRANEAN FEVER DISEASE IN AZERBAIJAN POPULATION}

\author{
L. Huseynova \\ R. Haqverdiyeva
}

Summary. Purpose of the work was to study mutations of MEFV gene of the Familial Mediterranean Fever disease in the population of the Republic of Azerbaijan. For this purpose, a complex of modern molecular-genetic methods based on polymerase-chain reaction has been used.

The 7 mutations of the MEFV gene have been identified: R761H M694I, M694V, V726A, R202Q, M680I and E148Q. Two mutations - E148Q and R202Q were located in exon 2, five mutations - R761H M694I, M694V, V726A, and M680I were found in exon 10.9 polymorphisms have been identified in the exons 2,3 and 5 of the MEFV gene.

To prevent Familial Mediterranean Fever hereditary disease in the population of the Republic of Azerbaijan, it is planned to carry out the medical-genetic counseling for families with genetic risk with the following prenatal diagnosis of the fetus in the next pregnancy.

Keywords: exon, population, mutation, gene, exon, chromosome, disease, nucleotide.

\author{
Гусейнова Лала Самеддин \\ Азербайджанский Медицинский Университет, \\ 2. Баку \\ royahuseynova2006@gmail.com \\ Агвердиева Рая Рустам \\ Азербайджанский Медицинский Университет, \\ 2. Баку \\ raya.hagverdiyeva@gmail.com
}

Аннотация. Приводятся результаты молекулярно-генетических исследований гена MEFV у больных с диагнозом: периодическая болезнь. Идентифицированы 7 мутаций гена MEFV: R761H, M694I, M694V, V726A, R2020, M680I и E148Q. Две мутаций —E148Q и R2020 расположены в 2-м, остальные 5 мутаций — R761H, M694I, M694V, V726A, M680I — в 10-м экзоне гена.

С целью профилактики периодической болезни в семьях с генетическим риском рождения больного ребенка, планируется проведение медико-генетческое консультироване с последующей пренатальной диагностики плода в первом триместре беременности с использованием молекулярно-генетических методов исследования.

Ключевые слова: экзон, популяция, мутация, хромосом, ген, нуклеотид.

В диагностике данного состояния. Встречаемость периодической болезни у различных этносов средиземноморского региона отличается, она наиболее высока у турок, арабов и армян, несколько ниже у евреев-сефардов, еще реже - у греков, итальянцев и испанцев. По некоторым данным, носительство патологического гена в определенных регионах затрагивает 20\% населения, а заболеваемость составляет 1:1000-2500. Периодическая болезнь наследуется по аутосомно-рецессивному типу и с одинаковой частотой поражает как мальчиков, так и девочек (1).

Долгое время этиология и патогенез периодической болезни оставались неизвестными, лишь достижения современной генетики позволили больше узнать об этом заболевании. Наиболее часто причиной данной патологии являются мутации гена MEFV, расположенного на 16-й хромосоме (16p13.3). Ген кодирует белок под названием маренострин, который выполняет функции 
одного из центральных регуляторов воспалительной реакции и первичного иммунного ответа. Маренострин затормаживает дегрануляцию нейтрофилов и угнетает их адгезивные свойства, тем самым ослабляя и ингибируя чрезмерную реакцию иммунной системы. При периодической болезни миссенс мутации гена MEFV приводят к изменению структуры маренострина, тем самым нарушая его функции. Это снижает порог дегрануляции нейтрофилов, что облегчает развитие острых воспалительных реакций и формирует клиническую картину периодической болезни. Кроме того, дефекты маренострина приводят к каскадным патологическим реакциям в иммунной системе и организме в целом. Значительно уменьшается активность ингибитора одного из компонентов системы комплемента - С5а. Последний постепенно накапливается в серозных оболочках, а при достижении высоких концентраций провоцирует бурную воспалительную реакцию $(1,4)$. Это обстоятельство объясняет определенные свойства периодической болезни - преимущественное поражение серозных оболочек, а также сезонность заболевания (для накопления достаточных концентраций С5а необходимо несколько месяцев). В некоторых случаях для периодической болезни характерно также раннее развитие амилоидоза, однако его патогенез остается неясным (5).

Все вышеперечисленные процессы возникают у гомозигот, при наличии у человека двух аллелей дефектного гена MEFV. Существует теория, согласно которой гетерозиготы из-за снижения ингибирования адгезивных свойств гранулоцитов обладают повышенной резистентностью к бактериальным инфекциям. Отчасти это может объяснить столь высокую встречаемость патологической формы гена и его носительства среди этносов средиземноморского региона. Кроме того, существуют указания, что некоторые формы периодической болезни обусловлены дефектом генов на 19-й хромосоме, однако точно идентифицировать их пока не удалось $(6,7,8)$.

Таким образом, целью наших исследований является молекулярно-генетические исследования периодической болезни у больных детей в Азербайджане.

\section{Материалы и метолы исследований}

Материалом для исследований являлась венозная кровь на антикоагулянте ЭДТА в количестве 2 мл. Проведен генетический скрининг 548 новорожденных из родильных домов Республики и г. Баку, а также 132 больных ребенка из НИИ Педиатрии МЗ Республики.

Геномную ДНК из венозной крови выделяли, используя готовые наборы QIA ampgenomic DNA and RNA kits фирмы QIAGEN, Германия. Интактность и количество выделенного геномного ДНК, а также амплификата после ПЦР определяли путем электрофореза на 1,7\%-ом агарозном геле с использованием электрофоретического аппарата и источника питания (Power Pac Basic Gel Doc $^{\mathrm{IM}} \mathrm{EZ}$ ) Imager, фирмы BioRad, США. При электрофорезе В качестве маркера для идентификации синтезированных фрагметов ДНК использовали DNA Ladder 100 bp (1).

Режим ПЦР был следующим: $95^{\circ} \mathrm{C}-2$ мин., $\left(95^{\circ} \mathrm{C}-30^{\mathrm{I}}\right.$, $58^{\circ} \mathrm{C}-30^{\mathrm{I}}, 78^{\circ} \mathrm{C}-2$ мин. 25 циклов), $72^{\circ} \mathrm{C}-10$ мин. и пауза при $4^{\circ} \mathrm{C}-10$ мин., и режим ПЦР для гена GALT1-95 ${ }^{\circ} \mathrm{C}-2$ мин., $\left(95^{\circ} \mathrm{C}-30^{\mathrm{I}}, 60^{\circ} \mathrm{C}-30^{\mathrm{I}}, 76^{\circ} \mathrm{C}-2\right.$ мин. 30 циклов), $72^{\circ} \mathrm{C}-10$ мин. и пауза при $4^{\circ} \mathrm{C}-10$ мин. ПЦР проводили на амплификаторе Professional Thermocycler фирмы Biometra, Германия.

Для очистки фрагментов ДНК после первой ступени ПЦР использовали набор магнитов: «Agencourt AMPure XP PCR purification» и SPRIPlate 96 Super Magnet Plate. Очищенные фрагменты ПЦР использовали для дальнейших исследований. Вторую фазу ПЦР проводили в режиме: $95^{\circ} \mathrm{C}-2$ мин., $\left(95^{\circ} \mathrm{C}-30^{\mathrm{I}}, 52^{\circ} \mathrm{C}-58^{\circ} \mathrm{C}-30^{\mathrm{I}}, 78^{\circ} \mathrm{C}-2\right.$ мин. 30 циклов), $72^{\circ} \mathrm{C}-10$ мин. и пауза на амплификаторе при $4^{\circ} \mathrm{C}-10$ мин.

Затем проводили стандартную процедуру в секвенаторе GENOME Lab GeXPTM Sequencing для определения нуклеотидной последовательности каждого фрагмента ДНК. Очищенные образцы генов АВ13130xI считываются в системе анализа цепей ДНК автоматически. Нуклеотидные цепи Seqscape V.2.7. запрограммированные полиморфизмы и соответствующие мутации были идентифицированы Blast Ce NCBI с нормальными нуклеотидными цепями MEFV (рис 1, 2).

\section{Результаты исслеАований и их обсу жАения}

Идентифицированы 7 мутаций гена MEFV: R761H, M694I, M694V, V726A, R202Q, M680I и E148Q у населения Азербайджанской Республики. Семь зафиксированные мутации были ранее идентифицированы в основном в турецкой популяции, поселяющий побережье Средиземного моря $(4,7,8)$.

Трое из 18 обследованных пациентов были гетерозиготами, восемь гомозиготами и семь компаунд-гетерозиготами.

В таблице 1 представлены полиморфизмы, обнаруженные в гене MEFV - смещения нуклеотидов, частота совпадений и экзоны, в которых они находятся.

Как показано в таблице 1, девять полиморфизмов были обнаружены в трех экзонах $(2,3,5)$ гена MEFV. 
Таблица 1. Частота полиморфизмов гена MEFV

\begin{tabular}{|l|l|l|l|l|}
\hline No & Полиморфизм & Экзон & Номер & Частота (\%) \\
\hline 1. & $306 \mathrm{~T} / \mathrm{C}(\mathrm{D} 102 \mathrm{D})$ & 2 & 8 & 22.22 \\
\hline 2. & $414 \mathrm{~A} / \mathrm{G}(\mathrm{G} 138 \mathrm{G})$ & 2 & 4 & 11.11 \\
\hline 3. & $442 \mathrm{G} / \mathrm{C}(\mathrm{E} 148 \mathrm{Q})$ & 2 & 5.56 \\
\hline 4. & $495 \mathrm{C} / \mathrm{A}(\mathrm{A} 165 \mathrm{~A})$ & 2 & 4 & 11.11 \\
\hline 5. & $605 \mathrm{G} / \mathrm{C}(\mathrm{R} 202 \mathrm{Q})$ & 2 & 2 & 5.56 \\
\hline 6. & $942 \mathrm{C} / \mathrm{T}(\mathrm{R} 314 \mathrm{R})$ & 2 & 6 & 16.67 \\
\hline 7. & $1422 \mathrm{G} / \mathrm{A}(\mathrm{G} 474 \mathrm{G})$ & 4 & 11.11 \\
\hline 8. & $1428 \mathrm{~A} / \mathrm{G}(\mathrm{G} 476 \mathrm{G})$ & 3 & 4 & 11.11 \\
\hline 9. & $1530 \mathrm{~T} / \mathrm{C}(\mathrm{D} 510 \mathrm{D})$ & 5 & 2 & 5.56 \\
\hline
\end{tabular}
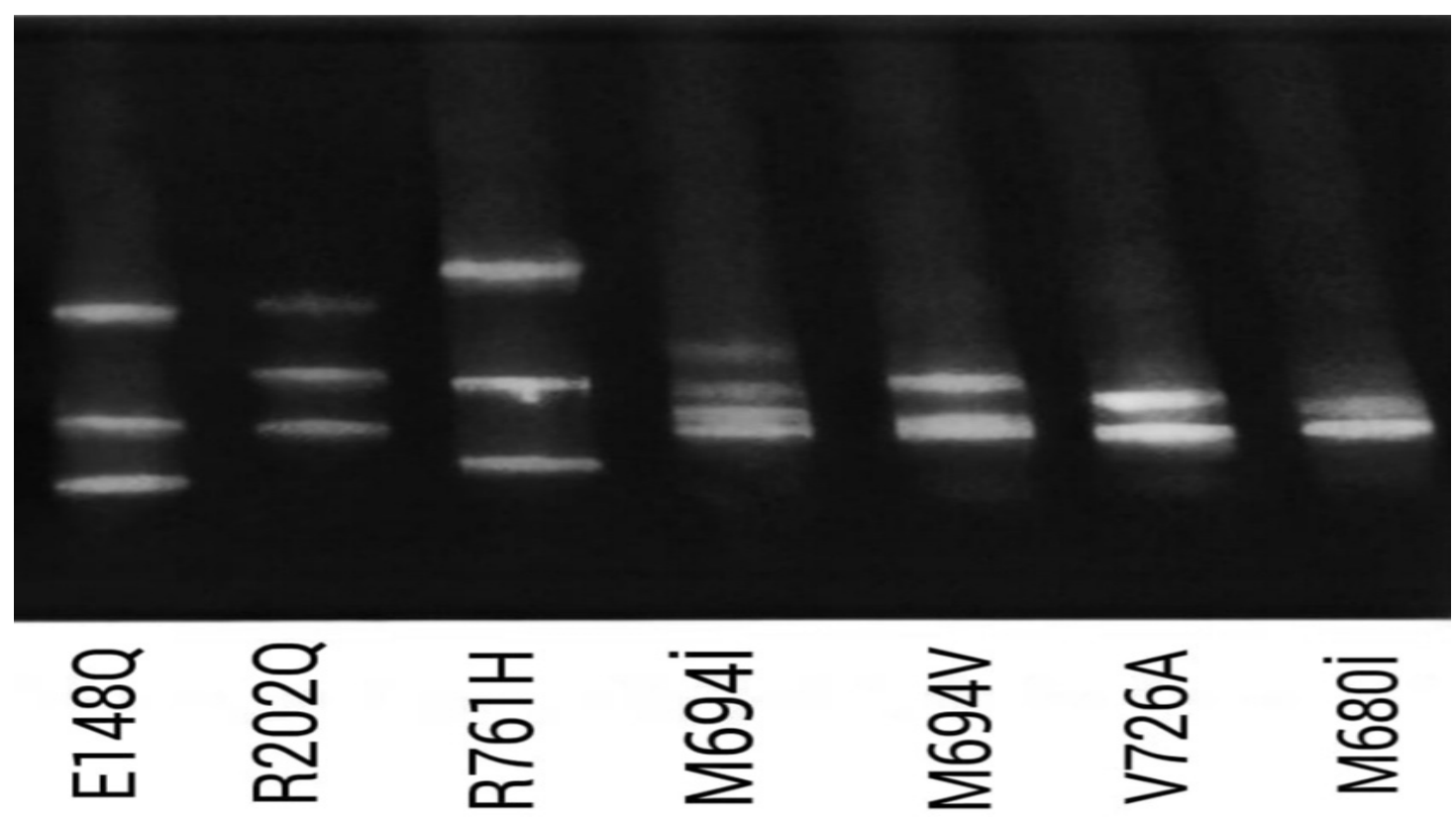

Рис. 1. Мутации E148Q и R202Q расположены в 2-м екзоне. Мутации M680I, R761H, M694I, M694V и V726A расположены в 10-м екзоне MEFV гена.

Пять полиморфизмов наблюдались во втором, один в третьем и три в пятом экзоне.

Полиморфизмы 414 A/G, 442 G/C, 495 C/A, 1422 G/A и 1428 A/G гена MEFV наблюдались у пациентов, чьи родители были родственниками и гомозиготами.

Высокие показатели полиморфизма были обнаружены для 306 Т/С (22,22\%) и 942 C/ Т (16,67\%) мутаций. Частота полиморфных генов 942 C/T, 605 G/ C и 1530 Т/C были самыми низкими - 5,56\%.

В таблице 2 представлены мутации, идентифицированные в гене MEFV.
Среди 18 исследованных пациентов выялена наибольшая частота мутации R761H гена MEFV, которая составляет 27,3\%. Две мутации - R202Q и E148Q были обнаружены в экзоне 2 (28,57\%), а остальные пять мутации - M860I, R761H, M694I, M694V и V726A, в экзоне 10 $(71,43 \%)$ гена MEFV.

Мутации R202Q и E148Q были обнаружены у одного гетерозиготного пациента, а две пациенты по мутациям R202Q и E148Q были компаунд-гетерозиготами (R202Q / $\mathrm{E} 148 \mathrm{Q})$. Мутация $\mathrm{R} 761 \mathrm{H}$ в гомозиготной форме была зарегистрирована в двух случаях, а в четырех случаях, для мутации M694I (R761H / M694I) наблюдается компаундность. Для мутации M694I выявлена комбиниро- 
Таблица 2. Частота мутаций гена MEFV

\begin{tabular}{|l|l|l|l|l|}
\hline Мутации & Номер & Частота (\%) & Частота фракций & Экзон \\
\hline E148Q & 3 & 9,1 & 0,0909 & 2 \\
\hline R202Q & 5 & 15,2 & 0,1515 & 2 \\
\hline M680I & 4 & 12,1 & 0,1212 & 10 \\
\hline R761H & 9 & 27,3 & 0,2727 & 10 \\
\hline M694I & 5 & 15,2 & 0,1515 & 10 \\
\hline M694V & 1 & 3,0 & 0,0303 & 10 \\
\hline V726A & 6 & 18,2 & 0,1818 & 10 \\
\hline
\end{tabular}

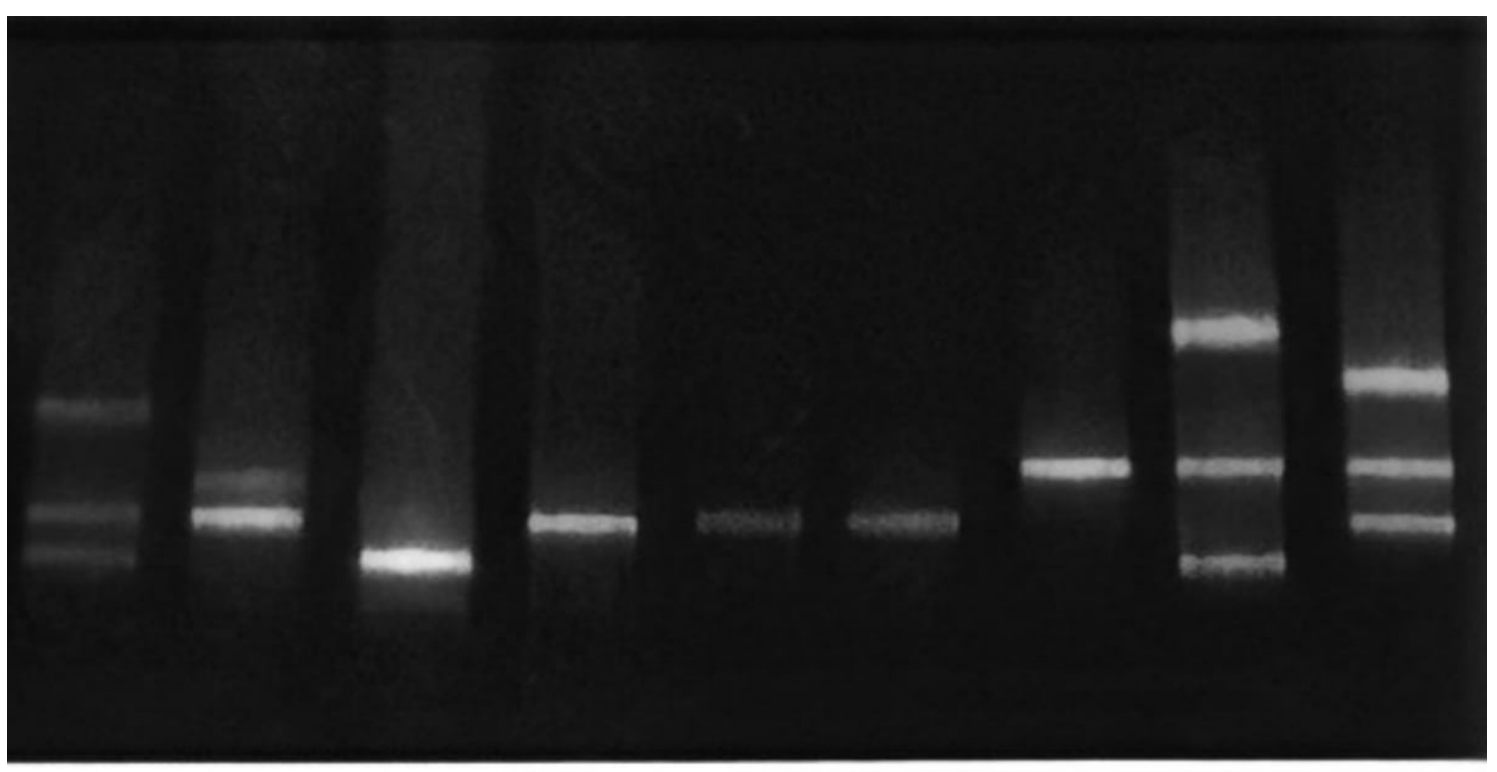

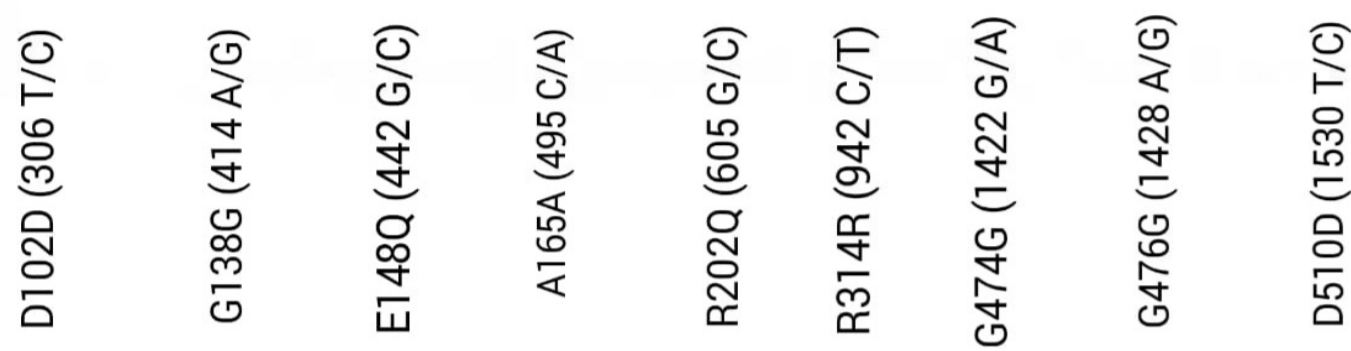

Рис. 2. Мутации D102D, G138G, E148Q, A165A и R202Q расположены в 2-м, мутация R314R расположены в 3-м екзоне, мутации G474G и D510D расположены в 5-м екзоне MEFV гена.

ванность с мутациями M694V и R202Q (M694I \M694V и M694I \R202Q). У двух пациентов мутация M680I обнаружена в гомозиготном состояние (M680I / M680I), гомозиготность по мутации V726A выявлена у трех пациентов. Следует отметить, что при гомозиготности по этой мутации, родители пациентов были родственниками. Согласно мировой литературе, пять мутаций - M694V, V726A, M694I, R202Q, M6801 и E148Q составляют 75\% всех найденных мутаций $(5,7,9,10,17)$. Пять мутаций из семи, обнаруженные нами, относятся к этой группе и составляют $57,6 \%$ от общего числа найденных мутаций.

Прогноз периодической болезни в значительной степени зависит от наличия или отсутствия амилоидоза. Если его нет, несмотря на тяжелые приступы заболевания, прогноз благоприятный, поскольку в межприступный период больные чувствуют себя удовлетворительно, продолжительность жизни практически не сокращается. В случае развития амилоидоза 
на фоне периодической болезни выживаемость пациентов резко снижается из-за поражения почек. Риск возникновения амилоидоза уменьшается при ранней диагностике средиземноморской семейной лихорадки и своевременно начатом лечении колхицином.

Профилактика периодической болезни возможна только в рамках пренатальной диагностики, которая рекомендуется в тех случаях, когда у обоих родителей имеется подозрение на носительство дефектного аллеля гена MEFV.

Чтобы предотвратить средиземноморскую семейную лихорадку родители 18 пациентов были проконсультированы врачом-генетиком для выяснения и прогноза рождения здорового ребенка, с учетом $25 \%$ риска рождения больного ребенка на следующую беременность. Поскольку большинство обследованные семьи находятся в репродуктивном возрасте, они гото- вятся к пренатальной диагностике плода при следующей беременности с их согласия.

\section{Зак^ючение}

Идентифицированы 7 мутаций гена MEFV:R761H, M694I, M694V, V726A, R202Q, M680I и E148Q у населения Азербайджанской Республики. Две мутаций - E148Q и R202Q расположены в 2-м, остальные 5 мутаций - R761H, M694I, M694V, V726A, M680I — в 10-м экзоне гена. В экзонах 2,3 и 5 гена MEFV было выявлено 9 полиморфизмов.

С целью профилактики периодической болезни в семьях с генетическим риском рождения больного ребенка планируется проведение медико-генетческое консультирование с последующей пренатальной диагностики плода в первом триместре беременности с использованием молекулярно-генетических методов исследования.

1. Бочков Н.П. Клиническая генетика. М. Медицина. 2002. 202 c.

2. Aksentijevich I., Torosyan Y., Samuels J., Centola M., Pras E, Chae J.J. Mutation and haplotypestudies of familial Mediterranean fever reveal new ancestral relationships and evidence for a high carrier frequency with reduced penetrance in the Ashkenazi Jewish population. Am J. Hum Genet. 1999;64(4):949-62. View ArticlePubMedPubMed CentralGoogle Scholar

3. Giaglis S., Papadopoulos V., Kambas K., Doumas M., Tsironidou V., Rafail S., et al. MEFV alterations and population genetics analysis in a large cohort of Greek patients with familial Mediterranean fever. Clin Genet. 2007;71(5):458-67.View ArticlePubMedGoogle Scholar

4. Debeljak M., Toplak N., Abazi N., Szabados B., Mulaosmanović V., Radović J., et al. The carrier rate and spectrum of MEFV gene mutations in central and southeastern European populations. Clin Exp Rheumatol. 2015;33(6 Suppl 94): S19-23.PubMedGoogle Scholar

5. Kümpfel T., Gerdes L.A., Wacker T., Blaschek A., Havla J., Krumbholz M., et al. Familial Mediterranean fever-associated mutation pyrin E148Q as a potential risk factor for multiple sclerosis. Mult Scler. 2012;18(9):1229-38.View ArticlePubMedGoogle Scholar

6. McKusick A. Mendelian inheritance in man. Tenth edition, London, 2002, p. 2115.

7. Ozturk A., Ozcakar B., Ekim M., Akar N. Is MEFV gene Arg202Gln (605G > A) A disease- causing mutation. Turk J Med Sci. 2008;38(3):205-8.G00gle Scholar

8. Sayın Kocakap D.B., Günel-Özcan A., Çabuk F., Ensari C. The frequency of Familial Mediterranean fever gene mutations and genotypes at Kirikkale and comparison with the mean of regional MEFV mutation frequency of Turkey. Mol Biol Rep. 2014;41(3):1419 